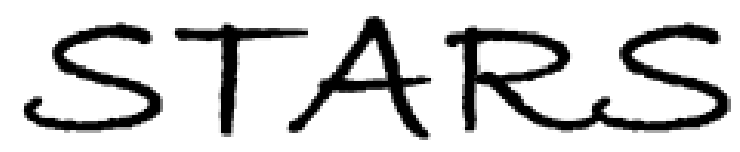

University of Central Florida

STARS

\title{
Influence of modifier oxides on the structural and optical properties of binary $\mathrm{TeO} 2$ glasses
}

C. Rivero

University of Central Florida

R. Stegeman

University of Central Florida

K. Richardson

University of Central Florida

G. Stegeman

University of Central Florida

G. Turri

University of Central Florida

Find similar works at: https://stars.library.ucf.edu/facultybib2000

University of Central Florida Libraries http://library.ucf.edu

See next page for additional authors

This Article is brought to you for free and open access by the Faculty Bibliography at STARS. It has been accepted for inclusion in Faculty Bibliography 2000s by an authorized administrator of STARS. For more information, please contact STARS@ucf.edu.

\section{Recommended Citation}

Rivero, C.; Stegeman, R.; Richardson, K.; Stegeman, G.; Turri, G.; Bass, M.; Thomas, P.; Udovic, M.; Cardinal, T.; Fargin, E.; Couzi, M.; Jain, H.; and Miller, A., "Influence of modifier oxides on the structural and optical properties of binary TeO2 glasses" (2007). Faculty Bibliography 2000s. 7572.

https://stars.library.ucf.edu/facultybib2000/7572

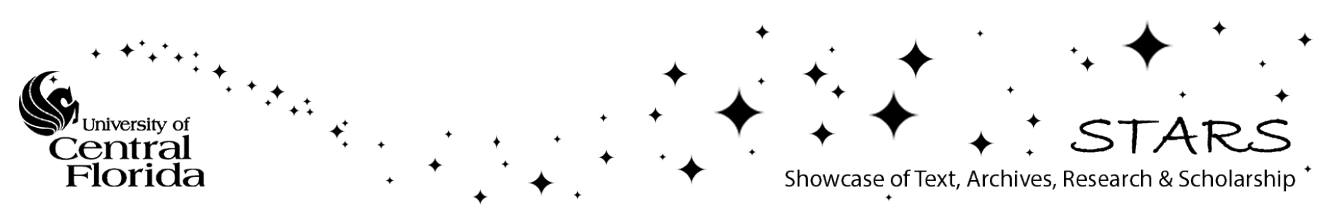




\section{Authors}

C. Rivero, R. Stegeman, K. Richardson, G. Stegeman, G. Turri, M. Bass, P. Thomas, M. Udovic, T. Cardinal, E. Fargin, M. Couzi, H. Jain, and A. Miller 


\section{Influence of modifier oxides on the structural and optical properties of binary $\mathrm{TeO}_{2}$ glasses}

Cite as: J. Appl. Phys. 101, 023526 (2007); https://doi.org/10.1063/1.2427102

Submitted: 02 September 2006 . Accepted: 05 November 2006 . Published Online: 26 January 2007

C. Rivero, R. Stegeman, K. Richardson, G. Stegeman, G. Turri, M. Bass, P. Thomas, M. Udovic, T. Cardinal, E. Fargin, M. Couzi, H. Jain, and A. Miller

\section{ARTICLES YOU MAY BE INTERESTED IN}

White emission materials from glass doped with rare Earth ions: A review AIP Conference Proceedings 1719, 020002 (2016); https://doi.org/10.1063/1.4943695

Study of structural, electrical, and dielectric properties of phosphate-borate glasses and glassceramics

Journal of Applied Physics 120, 051701 (2016); https://doi.org/10.1063/1.4958935

Structural, electronic, and optical properties of $\alpha, \beta$, and $\gamma-\mathrm{TeO}_{2}$

Journal of Applied Physics 107, 093506 (2010); https://doi.org/10.1063/1.3406135

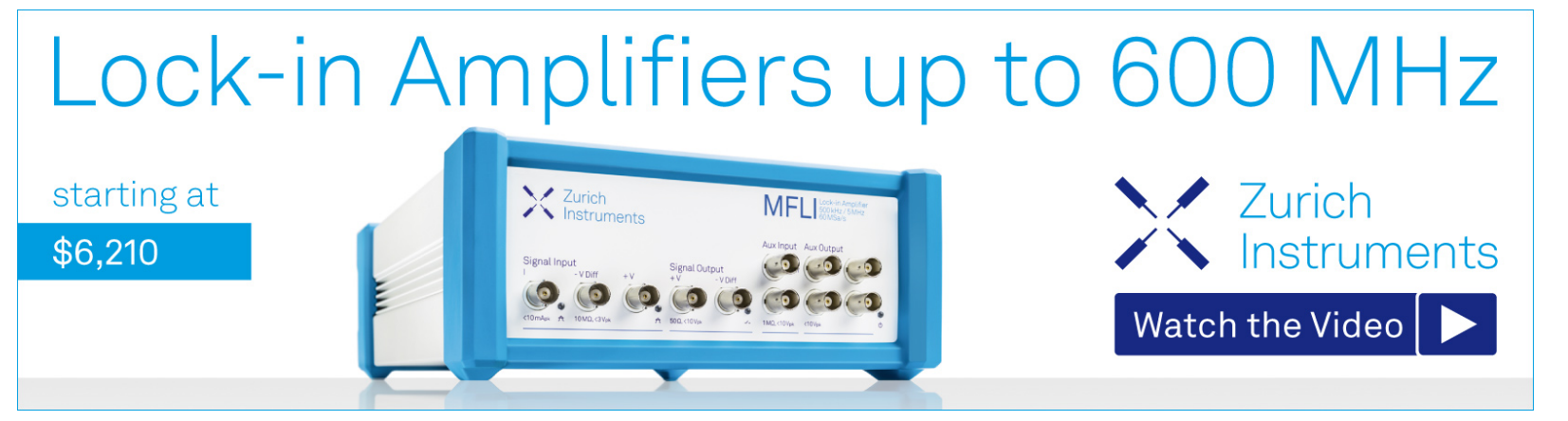




\title{
Influence of modifier oxides on the structural and optical properties of binary $\mathrm{TeO}_{2}$ glasses
}

\author{
C. Rivero, ${ }^{\text {a) }}$ R. Stegeman, K. Richardson, ${ }^{\text {b) }}$ G. Stegeman, G. Turri, and M. Bass \\ CREOL, The College of Optics and Photonics, University of Central Florida, \\ 4000 Central Florida Boulevard, Orlando, Florida 32816 \\ P. Thomas and M. Udovic ${ }^{\mathrm{c})}$ \\ Science des Procedes Ceramiques et Traitements de Surfaces, UMR6638 CNRS, \\ Faculte des Sciences et Techniques, 123 Avenue Albert Thomas, 87060 Limoges Cedex, France \\ T. Cardinal and E. Fargin \\ Institut de Chimie de la Matiere Condensee de Bordeaux, UPR 9048-CNRS, Université Bordeaux I, \\ 87 Avenue du Dr. Albert Schweitzer, 33608 Pessac Cedex, France \\ M. Couzi \\ Laboratoire de Physico-Chimie Moleculaire, UMR 5803-CNRS, Université Bordeaux I, Batinert A12, 33405 \\ Talence Cedex, France \\ H. Jain and A. Miller \\ Department of Material Science and Engineering, Lehigh University, Bethlehem, Pennsylvania 18015 \\ and Zettlemoyer Center for Surface Studies, Lehigh University, Bethlehem, Pennsylvania 18015
}

(Received 2 September 2006; accepted 5 November 2006; published online 26 January 2007)

Five different glass compositions with equal $\mathrm{TeO}_{2}$ molar concentration and various intermediate constituents were prepared to examine the influence of such intermediate species on the tellurite network. A correlation between the glasses' structural network and optical properties is presented. Peak Raman gain coefficients, on the order of 40 times the gain of $\mathrm{SiO}_{2}$, are reported in this paper. (C) 2007 American Institute of Physics. [DOI: 10.1063/1.2427102]

\section{INTRODUCTION}

Tellurium oxide-based glasses are considered to be promising materials for a broad range of optical applications. These glasses exhibit high linear and nonlinear refractive indices, their transparency window spans from the visible to the infrared region out to $7 \mu \mathrm{m}$, and they also exhibit high polarizabilities and Raman scattering cross sections. ${ }^{1-4}$ Due to all of these unique optical properties, $\mathrm{TeO}_{2}$-based glasses have emerged as promising candidates for Raman gain applications. ${ }^{5-11}$

This paper aims to identify how different intermediate glass constituents affect the tellurium glass network, and consequently the glass' resulting optical properties. Crucial properties such as thermal stability, absorption, and gain coefficients have been defined as metrics to identify candidate glass systems for future Raman amplification applications. For this purpose, five $\mathrm{TeO}_{2}$-based glasses were fabricated such that they all possess the same molar concentration of $\mathrm{TeO}_{2}$ atoms with different intermediate glass constituents. A correlation between the structural arrangement of the glass matrix and the optical properties of the glass is presented.

\footnotetext{
${ }^{a)}$ Author to whom correspondence should be addressed; electronic mail: crivero@mail.ucf.edu

${ }^{b}$ Present address: School of Materials Science and Engineering, Clemson University, 161 Sirrine Hall, Box 340971, Clemson, SC 29634.

${ }^{c}$ On leave from Jozef Stefan Institute, Jamova 39, 1000 Ljubljana, Slovenia.
}

\section{EXPERIMENT}

\section{A. Glass processing}

Five different binary $85 \mathrm{~mol} \% \mathrm{TeO}_{2}-15 \mathrm{~mol} \% x(x$ $=\mathrm{WO}_{3}, \mathrm{TiO}_{2}, \mathrm{NbO}_{2.5}, \mathrm{PbO}$, and $\mathrm{GaO}_{1.5}$ ) compositions were fabricated from appropriate quantities of reagent grade chemicals relevant to the different systems studied: $\mathrm{WO}_{3}$ (Interchim, 99\%+), $\mathrm{TiO}_{2}$ (Aldrich, 99.9\%), $\mathrm{Nb}_{2} \mathrm{O}_{5}$ (Aldrich, 99.5\%), $\mathrm{PbO}$ (Aldrich, 99.5\%), and $\mathrm{Ga}_{2} \mathrm{O}_{3}$ (Aldrich, 99.9\%). $\mathrm{TeO}_{2}$ was prepared by decomposition at $550{ }^{\circ} \mathrm{C}$ of commercial $\mathrm{H}_{6} \mathrm{TeO}_{6}$ (Aldrich, 99.9\%). The glasses were melted at $800{ }^{\circ} \mathrm{C}$ for $30 \mathrm{~min}$ in platinum crucibles. The melts were quenched between two brass blocks separated by a cylinder to obtain $1 \mathrm{~cm}$ diameter samples. The glasses were annealed at $40{ }^{\circ} \mathrm{C}$ below their glass transition temperature, and optically polished to a thickness of $2 \mathrm{~mm}$.

\section{B. Glass characterization}

The thermal stability of the glasses was determined by measuring the difference between the onset of the crystallization temperature $\left(T_{x}\right)$ and the glass transition temperature $\left(T_{g}\right)$, utilizing differential scanning calorimetry (DSC) and a heating rate of $10^{\circ} \mathrm{C} / \mathrm{min}$.

The density or volumetric weight of the different glass samples was measured by the Archimedes method in diethylphtalate at room temperature $\left(24^{\circ} \mathrm{C}\right)$. The accuracy of the density measurement is $\pm 0.02 \mathrm{~g} / \mathrm{cm}^{3}$.

The linear refractive index was measured at 532 and $1064 \mathrm{~nm}$, respectively, using the Brewster angle technique. The linear refractive index was obtained by fitting the experi- 
TABLE I. Chemical-physical-optical properties of different binary $\mathrm{TeO}_{2}$-based glasses .

\begin{tabular}{|c|c|c|c|c|c|c|}
\hline \multirow{2}{*}{$\begin{array}{c}\text { Glass Composition } \\
(\mathrm{mol} \%)\end{array}$} & \multirow{2}{*}{$\begin{array}{l}\text { Sample } \\
\text { code }\end{array}$} & \multicolumn{2}{|c|}{$\begin{array}{l}\text { Thermal } \\
\text { stability }\end{array}$} & \multirow{2}{*}{$\begin{array}{c}\text { Density } \\
\pm 0.02 \\
\left(\mathrm{~g} / \mathrm{cm}^{3}\right)\end{array}$} & \multicolumn{2}{|c|}{$\begin{array}{c}\text { Linear refractive index } \\
\qquad n(\lambda) \pm 0.02\end{array}$} \\
\hline & & $T_{g}\left({ }^{\circ} \mathrm{C}\right)$ & $T_{x}\left({ }^{\circ} \mathrm{C}\right)$ & & $n(532)$ & $n(1064)$ \\
\hline $85 \% \mathrm{TeO}_{2}-15 \% \mathrm{WO}_{3}$ & W15 & 348 & 421 & 5.89 & 2.16 & 2.12 \\
\hline $85 \% \mathrm{TeO}_{2}-15 \% \mathrm{TiO}_{2}$ & Ti15 & 356 & 427 & 5.34 & 2.06 & 2.08 \\
\hline $85 \% \mathrm{TeO}_{2}-15 \% \mathrm{NbO}_{2.5}$ & $\mathrm{Nb} 15$ & 347 & 440 & 5.44 & 2.11 & 2.06 \\
\hline $85 \% \mathrm{TeO}_{2}-15 \% \mathrm{PbO}$ & $\mathrm{Pb} 15$ & 291 & 317 & 6.07 & 2.09 & 2.05 \\
\hline $85 \% \mathrm{TeO}_{2}-15 \% \mathrm{GaO}_{1.5}$ & Ga15 & 327 & 372 & 5.47 & 2.02 & 1.99 \\
\hline
\end{tabular}

mentally obtained angular reflectance spectrum for TM polarization. The accuracy of the measurement depends on the surface quality of the sample. The reported accuracy of the apparatus was within \pm 0.02 .

The UV-vis-near IR (NIR) absorption spectra of the glasses were recorded with a Cary 500 spectrophotometer. The absorption coefficients at $1064 \mathrm{~nm}$ were obtained using two independent techniques, photothermal deflection spectroscopy (PDS) and a calorimetry technique, respectively. For the PDS setup, a stationary probe beam (HeNe laser, $\lambda$ $=632.8 \mathrm{~nm}$ ) and a moving pump beam [Nd:YAG (yttrium aluminum garnet) laser, $\lambda=1064 \mathrm{~nm}$ ] were sent colinearly into the sample. The fixed probe beam was centered on a quadrant detector (UDT Instruments, model 301-DIV), and its deflection (relative to the case where both the probe and the pump beams were perfectly spatially overlapped) was recorded. A Fabry-Pérot filter was used to transmit the probe beam and reject the pump beam from the quadrant detector. The deflection of the probe beam is produced by an index of refraction gradient in the sample, which in turn results from a corresponding temperature change due to the absorption of the exciting pump beam. The deflection of the probe beam is proportional to the absorption coefficient. ${ }^{12,13}$

In the case of the calorimetry measurement two different lasers, both emitting $\mathrm{TEM}_{00}$ mode $\mathrm{cw}$ light at $1064 \mathrm{~nm}$, were used: a commercial $\mathrm{Nd}: \mathrm{YVO}_{4}$ laser, with maximum output power of $130 \mathrm{~mW}$, for the more absorbing samples, and an in-house built Nd:YAG laser capable of up to $3.5 \mathrm{~W}$, for the low-absorption samples. The lasers were focused to spot of about $1 \mathrm{~mm}$ in diameter on the entrance surface of the sample. The samples were held by a piece of a monofilament fishing line glued to their edge and attached to a thermally isolated frame. This frame was mounted with $3^{\circ}$ of translational and rotational movements and positioned inside a styrofoam box, used to shield the experiment from thermal fluctuations. The sample temperature was measured by a precision temperature measurement system by GEC Instruments (model S4TC) allowing the simultaneous reading of four temperatures with a precision better than $10 \mathrm{mK}$ over a broad range of temperatures. Three temperature probes (Copper-Constantan thermocouples, type $\mathrm{T}$, gauge 40, $0.2 \mathrm{~mm}$ diameter) were glued to the sides of the sample. Care was taken to prevent any scattered laser light striking the temperature sensors. The basic idea behind this technique is to extract the absorptance, which is defined as the ratio between the power absorbed by the sample and the power of the incident laser, from recordings of temperature versus time histories of the samples when exposed to laser light. ${ }^{14,15}$ If the surface absorption is negligible, the absorption coefficient can be obtained from the measured absorptance.

The vertical-vertical (VV) polarized spontaneous Raman spectra of the five different binary $\mathrm{TeO}_{2}$-based glasses were acquired using a micro-Raman spectroscopy setup, with 514 and $752 \mathrm{~nm}$ excitations. An incoming vertically $(V)$-polarized laser beam was focused onto the front polished surface of the bulk sample, and the $V$-polarized Raman scattered signal was collected in the backscattering geometry with a $100 \times$ microscope objective, and it was spectrally analyzed with a spectrometer and a charge coupled device (CCD) detector (Andor, model FI UV), with a typical resolution of about $6 \mathrm{~cm}^{-1}$. The Rayleigh line was suppressed with a holographic notch filter.

X-ray photoelectron spectroscopy (XPS) spectra were recorded using a Scienta 300 ESCA (Zettlemoyer Center for Surface Studies, Lehigh University) at a vacuum of $\sim 10^{-9}$ Torr. A monochromatic Al $K \alpha$ x-ray source was used for the analysis, and a low energy electron flood gun was used for charge compensation. Both survey scan and individual high resolution scans were recorded. The bulk glass samples were scraped inside the XPS vacuum chamber to expose fresh bulk material, and the core-level spectra were obtained on the newly generated surfaces. Pure paratellurite $\left(\mathrm{TeO}_{2}\right)$ and $\mathrm{Tl}_{2} \mathrm{TeO}_{3}$ crystals were used as reference materials as they are sources for the $\mathrm{TeO}_{4}$ and isolated $\mathrm{TeO}_{3}$ units, respectively.

\section{RESULTS}

Table I illustrates the five compositions studied along with their respective thermal stability, density, and refractive index data.

The results shown in Table I illustrate that the addition of lead oxide $(\mathrm{PbO})$ increases the density, but decreases the thermal stability of the glass (lowest $T_{x}-T_{g}$ value). On the other hand, the composition containing $15 \% \mathrm{NbO}_{2.5}$ exhibits the highest thermal stability $\left(T_{x}-T_{g}=93{ }^{\circ} \mathrm{C}\right)$.

Figure 1 shows the corresponding absorption band edge for the five different binary $\mathrm{TeO}_{2}$ glass samples containing equal $\mathrm{TeO}_{2}$ molar concentration. As shown in the figure, the energy gap is lower for the tungsten sample (W15). Also, all these glasses exhibit an absorption tail up to $550 \mathrm{~nm}$.

Figure 2 illustrates an example of the PDS response for 


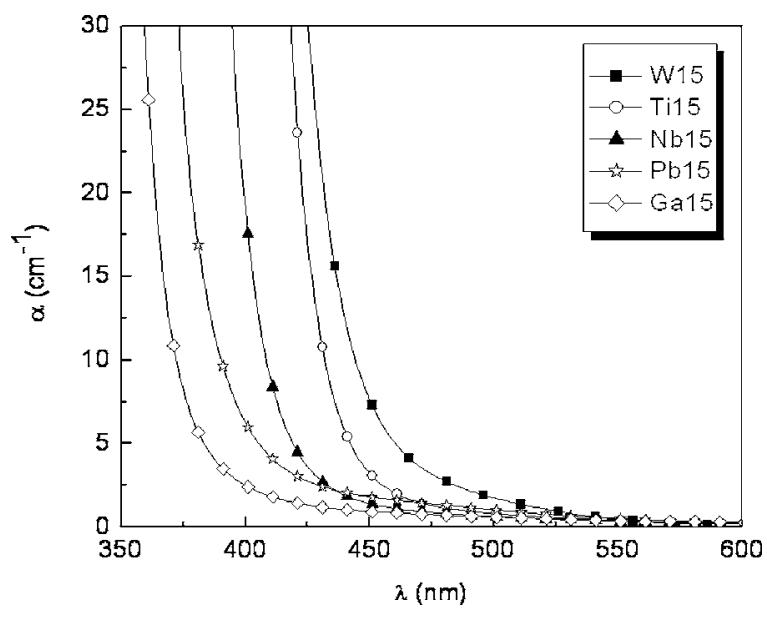

FIG. 1. Absorption edge spectra of $85 \% \mathrm{TeO}_{2}-15 \% x\left(x=\mathrm{WO}_{3}, \mathrm{TiO}_{2}\right.$, $\mathrm{NbO}_{2.5}, \mathrm{PbO}$, and $\mathrm{GaO}_{1.5}$ ) compositions.

composition $85 \% \mathrm{TeO}_{2}-15 \% \mathrm{NbO}_{1.5}$ as a function of increasing pump power. The angular deviation, proportional to the variation in the voltage readings of the quadrant detector, is plotted against the pump beam displacement. Notice that the higher the pump power the higher the deviation of the probe beam.

A typical temperature variation versus time plot obtained from the calorimetry measurements on the glasses is shown in Fig. 3 for composition $85 \% \mathrm{TeO}_{2}-15 \% \mathrm{WO}_{3}$, for different laser irradiation times.

Figures 4(a) and 4(b) illustrate the VV polarized Raman spectra of the five different binary tellurite glass compositions with equal molar concentration of tellurium oxide, for excitation wavelengths of 514 and $752 \mathrm{~nm}$, respectively. The relative Raman gain coefficient, normalized to $\mathrm{SiO}_{2}$, were obtained according to

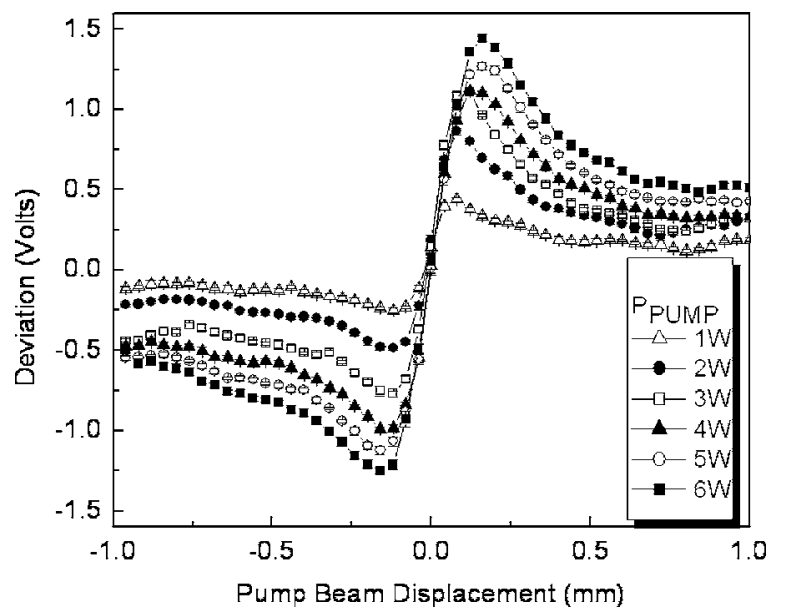

FIG. 2. Typical PDS response for composition $85 \% \mathrm{TeO}_{2}-15 \% \mathrm{NbO}_{2.5}$, for different pump powers. Pump wavelength, $\lambda_{\text {pump }}=1064 \mathrm{~nm}$.

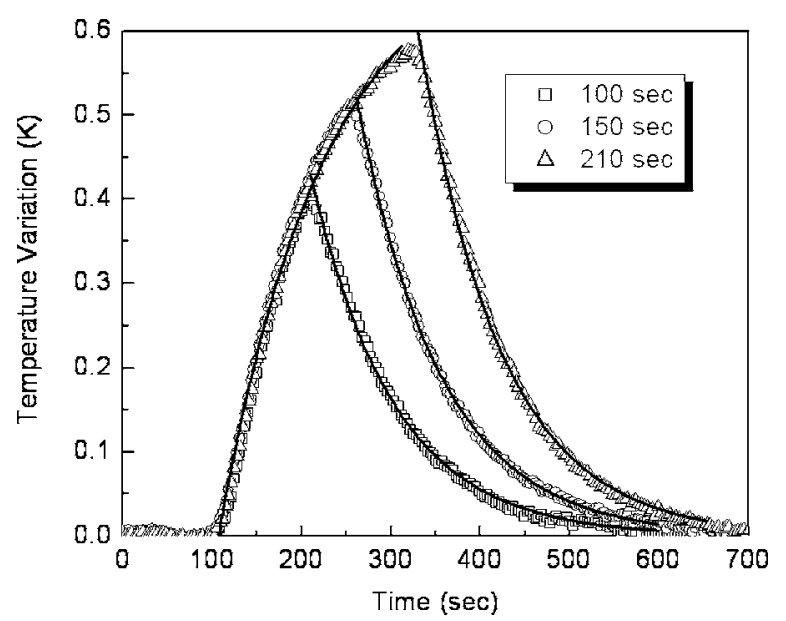

FIG. 3. Temperature variation vs time plot for composition $85 \%$ $\mathrm{TeO}_{2}-15 \% \mathrm{WO}_{3}$, for different laser irradiation times. Full lines are obtained as best fit on the heating and cooling edge independently, assuming infinite thermal conductivity [Eqs. (2) and (3)].
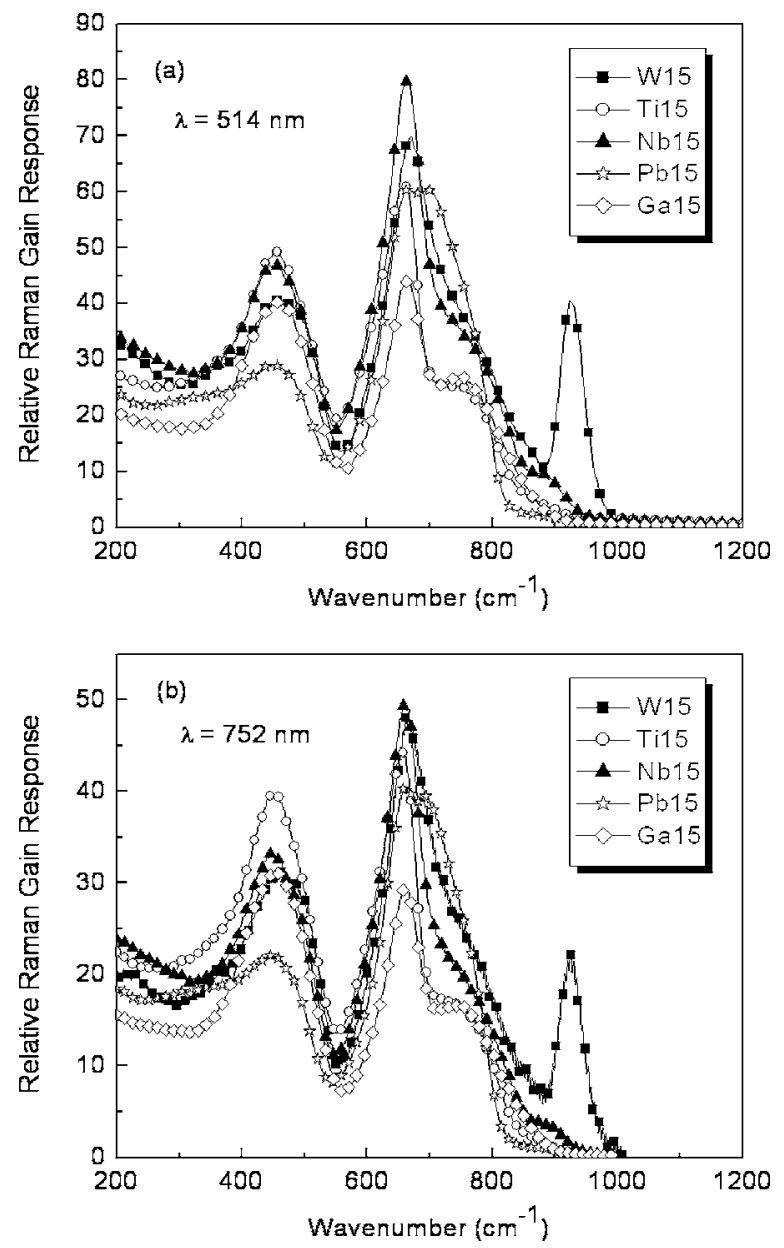

FIG. 4. Raman gain spectra for the $85 \% \mathrm{TeO}_{2}-15 \% x\left(x=\mathrm{WO}_{3}, \mathrm{TiO}_{2}\right.$, $\mathrm{NbO}_{2.5}, \mathrm{PbO}$, and $\mathrm{GaO}_{1.5}$ ) compositions calculated from absolute spontaneous Raman cross-section measurements at $514 \mathrm{~nm}$ (a) and $752 \mathrm{~nm}$ (b), normalized to $\mathrm{SiO}_{2}$. 


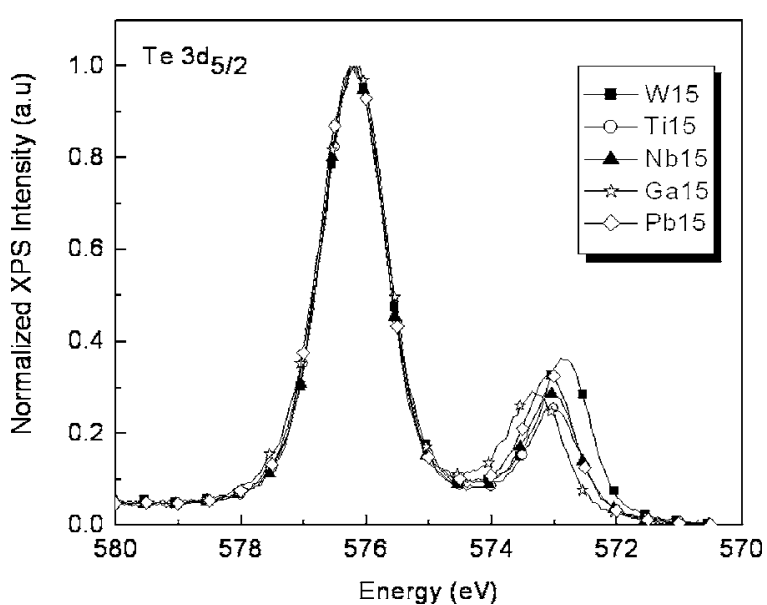

FIG. 5. XPS spectra of the Te $3 d_{5 / 2}$ peak for the $85 \% \mathrm{TeO}_{2}-15 \% x(x$ $=\mathrm{WO}_{3}, \mathrm{TiO}_{2}, \mathrm{NbO}_{2.5}, \mathrm{PbO}$, and $\mathrm{GaO}_{1.5}$ ) compositions.

$$
\begin{aligned}
\frac{g_{R \mathrm{TeO}_{2}}^{r, k}\left(\omega_{P}-\Omega_{\beta}^{r}\right)}{g_{R \mathrm{SiO}_{2} \beta^{\prime}}^{r^{\prime}, k^{\prime}}\left(\omega_{P}-\Omega_{\beta^{\prime}}^{r^{\prime}}\right)}= & \frac{\left(\omega_{P}-\Omega_{\beta^{\prime}}^{r^{\prime}}\right)^{3}}{\left(\omega_{P}-\Omega_{\beta}^{r}\right)^{3}} \frac{n\left(\omega_{P}-\Omega_{\beta}^{r}\right) n^{\prime}\left(\omega_{P}\right)}{n^{\prime}\left(\omega_{P}-\Omega_{\beta^{\prime}}^{r^{\prime}}\right) n\left(\omega_{P}\right)} \\
& \times \frac{\left[1-R^{\prime}\left(\omega_{P}-\Omega_{\beta^{\prime}}^{r^{\prime}}\right)\right]\left[1-R^{\prime}\left(\omega_{P}\right)\right]}{\left[1-R\left(\omega_{P}-\Omega_{\beta}^{r}\right)\right]\left[1-R\left(\omega_{P}\right)\right]} \\
& \times \frac{I_{\beta}^{k, r}\left(\omega_{P}-\Omega_{\beta}^{r}\right)}{I_{\mathrm{inc}}\left(\omega_{P}\right)} \frac{I_{\mathrm{inc}}{ }^{\prime}\left(\omega_{P}\right)}{I_{\beta^{\prime}}^{r^{\prime}, k^{\prime}}\left(\omega_{P}-\Omega_{\beta^{\prime}}^{r^{\prime}}\right)},
\end{aligned}
$$

where all the unprimed parameters belong to the $\mathrm{TeO}_{2}$ glasses, and the primed parameters belong to fused silica. In this equation, $\omega_{P}$ represents the pump frequencies (514 and $752 \mathrm{~nm}$, respectively), and $\Omega_{\beta}^{r}$ represents the Raman vibration of the $\beta$ th mode and $r$ th glass constituent, as reported in Ref. 16.

From Figs. 4(a) and 4(b) one can clearly observe almost a factor of two discrepancy between the spontaneous scattering measurements conducted in the visible and the NIR region, even after all the appropriate dispersion corrections were applied, as given by Eq. (1).

The XPS spectra of the Te $3 d_{5 / 2}$ peak for the five different binary $\mathrm{TeO}_{2}$-based glasses with equal $\mathrm{TeO}_{2}$ mole percentage and differing intermediate species have been investigated in order to evaluate the ratio $\mathrm{TeO}_{4} / \mathrm{TeO}_{3}$ units in the resulting glass. The results of these measurements are shown in Fig. 5. The XPS spectra show different energy distributions and peak intensities for the $573 \mathrm{eV}$ Te $3 d_{5 / 2}$ peak.

\section{DISCUSSION}

Pure $\mathrm{TeO}_{2}$ glass is difficult to form due to crystallization of the former compound without other constituents. However, the results shown in Table I indicate that addition of $d^{0}$ metal ions in the tellurite network appears to increase the thermal stability of glass, which is related to the $T_{x}-T_{g}$ value (around $75^{\circ} \mathrm{C}$ ), an important factor for fiberization purposes. The addition of a $d^{10}$ ion such as Ga confers a slightly lower thermal stability, with $\left(T_{x}-T_{g}\right)$ around $45^{\circ} \mathrm{C}$, but the $T_{x}-T_{g}=26{ }^{\circ} \mathrm{C}$ obtained for the addition of the $5 s^{2} \mathrm{~Pb}$ ion shows that the limit of devitrification is quite attained.

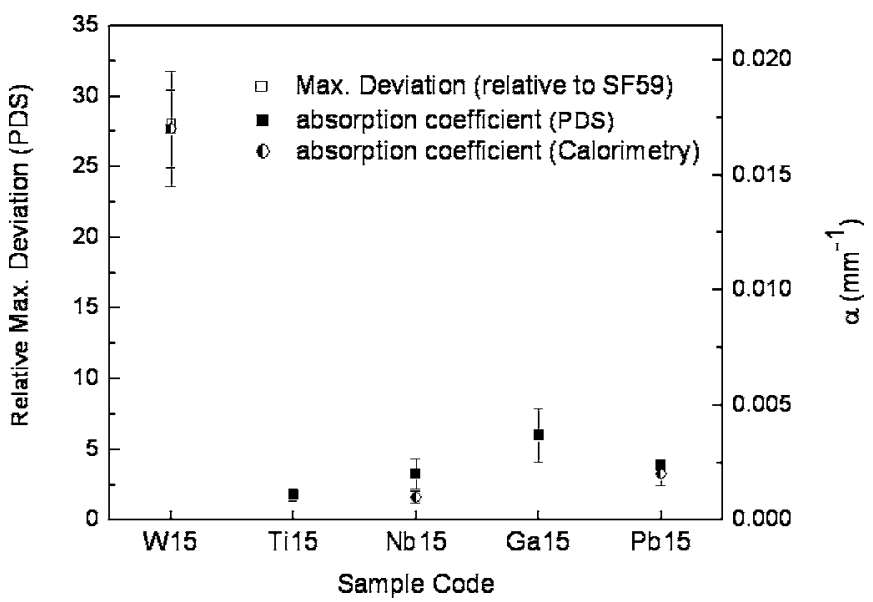

FIG. 6. Absorption coefficient of $85 \% \mathrm{TeO}_{2}-15 \% x\left(x=\mathrm{WO}_{3}, \mathrm{TiO}_{2}, \mathrm{NbO}_{2.5}\right.$, $\mathrm{PbO}$, and $\mathrm{GaO}_{1.5}$ ) compositions, at $1064 \mathrm{~nm}$.

The compositions containing the heaviest ions such as $\mathrm{Pb}$ and $\mathrm{W}$ exhibit the highest densities, and their relatively high linear index values are among the highest refractive index values reported for oxide-based glasses. These high indices are characteristic of glasses containing highly polarizable species such as $d^{0}$ and/or $n s^{2}$ ions, and typically yield correspondingly high nonlinear refractive indices as well. ${ }^{1}$

Figure 1 illustrates the shift of the absorption edge of the five $\mathrm{TeO}_{2}$-based samples with different intermediate species. In the case when $d^{0}$ ions are added as the intermediate glass constituents, the shift in the absorption band edge is in agreement with calculations reported for titanium, niobium, and tungsten oxide single crystal structures. The absorption edge position of the three compositions containing $d^{0}$ ions $\left(\mathrm{W}^{6+}\right.$, $\mathrm{Nb}^{5+}$, and $\mathrm{Ti}^{4+}$ ) shows clear trends, as suggested by the calculations performed on the single crystal structures, in which the effective Sellmeier gaps are $4.5 \mathrm{eV}$ for $\mathrm{WO}_{3}, 5.5 \mathrm{eV}$ for $\mathrm{TiO}_{2}$, and $6.8 \mathrm{eV}$ for $\mathrm{Nb}_{2} \mathrm{O}_{5}$, respectively, ${ }^{17}$ in good agreement with the results shown in Fig. 1.

Absorption is another crucial factor for deployment of such glasses as Raman amplifiers as it serves as a loss mechanism which will ultimately limit any gain offered by the material. Hence, the absorption coefficient of the five different samples was acquired by fitting the PDS and calorimetry results, as shown in Figs. 2 and 3, at a $1064 \mathrm{~nm}$ pump wavelength. $1064 \mathrm{~nm}$ was chosen as the wavelength of choice as it was easily obtained and is close to the telecommunication wavelength region of interest where candidate glasses would be employed. In the PDS setup, the amplitude of the deflection of the probe beam is related, to first order, to the absorption of the material. More rigorously, $\Phi^{\mathrm{MAX}}$ $\propto(d n / d T)(\alpha P / k)$, where $P$ is the pump intensity and $k$ is the thermal conductivity. ${ }^{12,13}$ Since the value of $k$ is also unknown, we conducted the same measurement at $532 \mathrm{~nm}$, where the absorption of the material can be obtained using other tools such as the Cary 500 spectrophotometer, thus allowing us to correct for $d n / d T$ and $k$. Using this information, the absorption coefficients at $1064 \mathrm{~nm}$ were extrapolated for the five different binary compositions $85 \% \quad \mathrm{TeO}_{2}$ $-15 \% x\left(x=\mathrm{WO}_{3}, \mathrm{TiO}_{2}, \mathrm{NbO}_{2.5}, \mathrm{PbO}\right.$, and $\left.\mathrm{GaO}_{1.5}\right)$, as depicted in Fig. 6. Moreover, in order to corroborate the PDS 
results, the calorimetry measurements were conducted in three of the samples. In the calorimetry experiment, the signal is proportional to $\left(P / m c_{P}\right)(A \gamma)$, where $P$ is the laser power, $m$ and $c_{P}$ are the sample mass and specific heat, respectively, $A$ is the absorptance, and $\gamma$ is a coefficient that accounts for all the sample thermal losses. ${ }^{14,15}$ In our experiment $P=1 \mathrm{~W}, m \approx 1 \mathrm{~g}, c_{P} \approx 0.5 \mathrm{~J} / \mathrm{g} \mathrm{K}$, and $\gamma \approx 0.01 \mathrm{~s}^{-1}$, thus the minimum signal that can be measured over the noise corresponds to an absorptance of $0.01 \%$ or $100 \mathrm{ppm}$. For samples with $0.1 \%$ absorptance the signal is one order of magnitude higher than the noise. Within the hypothesis of homogeneity and infinite thermal conductivity of the sample, the temperature variation versus time is thus given by

$$
\Delta T(t)=\frac{A P}{\gamma m c_{p}}\left\{1-\exp \left[-\gamma\left(t-t_{\text {start }}\right)\right]\right\} \text { during irradiation }
$$

and

$$
\begin{aligned}
\Delta T(t)= & \frac{A P}{\gamma m c_{p}}\left\{\exp \left[-\gamma\left(t-t_{\text {stop }}\right)\right]-\exp \left[-\gamma\left(t-t_{\text {start }}\right)\right]\right\} \\
& \text { after irradiation }
\end{aligned}
$$

where $t_{\text {start }}$ and $t_{\text {stop }}$ are the time at which the laser is turned on and off, respectively. $A, P, m, c_{P}$, and $\gamma$ are the previously defined quantities. The absorptance for each sample can be obtained by fitting the measured data using Eqs. (2) and (3) where $A$ and $\gamma$ are free parameters to achieve the fit, as shown in Fig. 3. As illustrated in Fig. 6, there is excellent agreement between the two sets of absorption data obtained by different techniques, reinforcing the validity of the data obtained from the two different measurement techniques.

The results shown in Fig. 6 illustrate that these glasses exhibit absorption coefficient values on the order of few $\mathrm{dB} / \mathrm{m}\left(\sim 10^{-3} \mathrm{~mm}^{-1}\right)$ at $1064 \mathrm{~nm}$. The enhanced absorption coefficient observed for the glass W15 is attributed to impurities present in the starting raw materials, which after absorption would induce overheating interference. A trace of copper on the starting $\mathrm{WO}_{3}$ material was detected, using electron paramagnetic resonance (EPR) technique, identifying the presence of $\mathrm{Cu}^{2+}$ which can be responsible for the absorption in the near IR. Although the losses are relatively high, one should point out that the processing conditions for these glasses were not fully optimized in order to obtain the highest optical quality. Moreover, the optical losses of these glasses are expected to decrease at $1.5 \mu \mathrm{m}$, which is closer to the wavelength range where these Raman amplifiers will be deployed in a telecommunication system. In fact, Mori et al. have shown a similar $\mathrm{TeO}_{2}$-based Raman fiber amplifier exhibiting a loss of $20 \mathrm{~dB} / \mathrm{km}\left(\alpha=4.6 \times 10^{-6} \mathrm{~mm}^{-1}\right)$ at $1.5 \mu \mathrm{m} .{ }^{5}$ As stated in Ref. 8, this last mentioned sample has a composition of $78 \% \mathrm{TeO}_{2}-5 \% \mathrm{ZnO}-12 \% \mathrm{Li}_{2} \mathrm{O}-5 \% \mathrm{Bi}_{2} \mathrm{O}_{3}$ (mol \%).

From the results shown in Figs. 4(a) and 4(b) one can clearly observe a factor of two discrepancy between the spontaneous Raman cross-section measurements conducted at 514 and $752 \mathrm{~nm}$, even after the appropriate dispersion factors are applied. These wavelength corrections, explicitly reported in Eq. (1), should lead to a constant Raman gain coefficient value that spans throughout the entire transparency range; ${ }^{18,19}$ however, as previously reported in Ref. 16, this enhancement in the Raman gain response of the material in the visible range is due to an inherent dispersion of the Raman susceptibility tensor, and a resonance enhancement phenomenon that occurs when these measurements are conducted near the absorption band edge of the material. Nonetheless, from the results obtained in the Raman spectral measurements illustrated in Figs. 4(a) and 4(b), one can clearly see that the main Raman bands are primarily related to the Te-O vibrations. ${ }^{4}$ The main bands around 450, 665, and $750 \mathrm{~cm}^{-1}$ are, respectively, attributed to the simple and double bridges $\mathrm{Te}-\mathrm{O}-\mathrm{Te}$ stretching vibrations, $\mathrm{TeO}_{4}$ bipyramidal, and $\mathrm{TeO}_{3+1}$ distorted sites, where one axial bond is elongated and the other one shortens. The geometry of those distorted sites can converge to pure $\mathrm{TeO}_{3}$ trigonal pyramidal units, a signature which is observed at lower energies, around $725 \mathrm{~cm}^{-1}$. The band at $930 \mathrm{~cm}^{-1}$ for the tungstentellurite glass was previously assigned to the stretching vibrations of the highly distorted octahedral sites $\mathrm{WO}_{4+2}$ in this system with nonbonding oxygen atoms. ${ }^{20}$ Also notice the factor of two discrepancy between the peak Raman gain response at the $\mathrm{TeO}_{4}$ vibration for the samples containing $\mathrm{WO}_{3}, \mathrm{Nb}_{2} \mathrm{O}_{5}, \mathrm{TiO}_{2}$, and $\mathrm{PbO}$, as compared to $\mathrm{Ga}_{2} \mathrm{O}_{3}$. This may be due to the fact that the presence of $\mathrm{W}^{6+}, \mathrm{Nb}^{5+}, \mathrm{Ti}^{4+}$, and $\mathrm{Pb}^{2+}$ ions further enhances the polarizability of the glasses due to the presence of $d^{0}$ ions or Lewis $n s^{2}$ lone pair electrons, which are also considered to be highly polarizable species. ${ }^{1,17}$ This can be verified when comparing the refractive indices of the glasses, with the gallium-tellurite glass exhibiting the lowest value. As a matter of fact, previous study showed the gallium structural behavior is particular, playing both the role of a modifier in octahedral sites and a formative one in tetrahedral sites, which is not the case for other compositions, where $\mathrm{Ti}, \mathrm{Nb}, \mathrm{W}$, and $\mathrm{Pb}$ are shown to act as modifiers. ${ }^{20,21}$ Moreover, one can also observe that the polarizability of the $\mathrm{TeO}_{3}$ vibration is further enhanced by the presence of $\mathrm{Pb}$ ions in the vicinity of these $\mathrm{TeO}_{3}$ entities. The corresponding peak appears around $725 \mathrm{~cm}^{-1}$, which seems to be the signature of isolated ionic $\mathrm{TeO}_{3}$ entities. This enhancement of the Raman hyperpolarizability of the $\mathrm{TeO}_{3}$ vibration could be related to the manner in which $\mathrm{Pb}$ enters the tellurium-based network as a modifier. The progress (kinetics) of the transformation of $\mathrm{TeO}_{4}$ into $\mathrm{TeO}_{3}$ through $\mathrm{TeO}_{3+1}$ units depends on modifier size and charge upon addition to a pure or $\mathrm{TeO}_{2}$-rich glass; in the glasses examined here, the addition of lead appears to stimulate this transformation faster as compared to the other modifier species, despite the identical molar quantity of the specific modifier species. ${ }^{22}$ Consequently, the role of the modifying species in breaking up the bridging oxygen network is further evidenced for the band at $450 \mathrm{~cm}^{-1}$ (attributed to the Te-O-Te bridge vibration), for all modifiers. Note that the intensity of this band is lower as compared to those at higher frequencies intensity, providing an indication as to the extent by which the modifier contributes to the depolymerization of the glassy tellurite framework and the progress of this $\mathrm{TeO}_{4} /\left(\mathrm{TeO}_{3}\right.$ or $\left.\mathrm{TeO}_{3+1}\right)$ transformation.

In order to obtain an indication of the quantities of $\mathrm{TeO}_{3}$, 


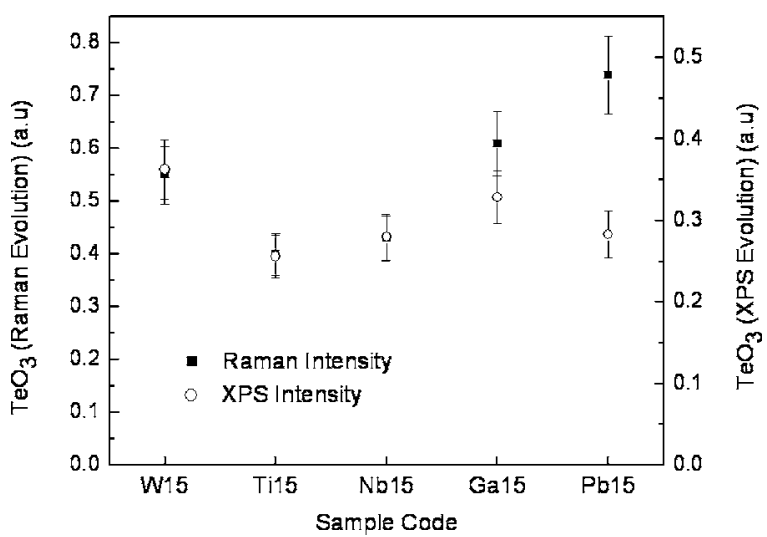

FIG. 7. Evolution of the $\mathrm{TeO}_{3}$ trigonal pyramidal units, normalized to $\mathrm{TeO}_{4}$ bipyramidal units from Raman and XPS spectra decomposition.

$\mathrm{TeO}_{4}$, and their ratio in these glasses, an XPS experiment was conducted. The XPS spectra shown in Fig. 5 illustrate two distinct Te $3 d_{5 / 2}$ peaks. Each XPS spectra can be decomposed into a spectrum comprised of five peaks attributable to five different structural units: $\mathrm{TeO}_{4},\left(\mathrm{TeO}_{3}\right)^{-}, \mathrm{TeO}_{3+1}$, $\left(\mathrm{Te}_{2} \mathrm{O}_{5}\right)^{2+}$, and $\left(\mathrm{TeO}_{3}\right)^{2-}$, as given in Ref. 23. Unfortunately, both the $\mathrm{TeO}_{4}$ and $\left(\mathrm{TeO}_{3}\right)^{-}$units are convolved within the main $\mathrm{Te} 3 d_{5 / 2}$ peak at $576.2 \mathrm{eV}$, hence in these circumstances it is more suitable to speak about the evolution of "non- $\mathrm{TeO}_{4}$ " units (i.e., the ratio between the 573 and $576 \mathrm{eV}$ XPS peaks). Similar amounts of $\mathrm{TeO}_{3}$ units have been found in all glasses. Nevertheless, the intensity of the band around $750 \mathrm{~cm}^{-1}$, obtained by the decomposition of each glass' Raman spectra, is definitely strongly related to the XPS signal around $573 \mathrm{eV}$ as shown in Fig. 7. If we compare the $\mathrm{TeO}_{3}$ to $\mathrm{TeO}_{4}$ ratio from Raman and XPS for the glass compositions containing the $d^{0}$ ions, one might expect a similar behavior for the Raman and XPS, since these units have generally the same octahedral structure, and hence, one would expect them to exhibit almost the same polarizability. Figure 7 illustrates the evolution of the $\mathrm{TeO}_{3}$ to $\mathrm{TeO}_{4}$ ratio (with $\mathrm{TeO}_{4}$ normalized to 1 ) for the five glasses examined, determined from the ratio of the maximum intensity value of the fitting of the 750 and $665 \mathrm{~cm}^{-1}$ Raman bands and 573 and $576 \mathrm{eV}$ Te $3 d_{5 / 2}$ XPS peaks, respectively. As expected, there is a clear trend in the evolution of the $\mathrm{TeO}_{3}$ to $\mathrm{TeO}_{4}$ units for the compositions containing $d^{0}$ species, indicating that the $750 \mathrm{~cm}^{-1}$ Raman band is directly related to the $573 \mathrm{eV}$ XPS peak. It is important to note that the enhanced discrepancy depicted in Fig. 7 for the Pb15 sample, as compared to the $\mathrm{TeO}_{3}$ ratio obtained from the Raman decomposition and the XPS data, is related to the enhancement in the polarizability of modified $\mathrm{TeO}_{3}$ groups which are affected by the presence of lead ions in the vicinity of these $\mathrm{TeO}_{3}$ entities possessing also a lone pair of electrons.

From the results obtained from the XPS and Raman data, one can conclude that the structural rearrangement inside the tellurium network, i.e., the transformation of the $\mathrm{TeO}_{4}$ bipyramidal units into the $\mathrm{TeO}_{3}$ trigonal pyramids, can be directly correlated with the associated optical property changes in the glass. For instance, a similar trend to that observed for the $573 \mathrm{eV}$ Te $3 d_{5 / 2}$ XPS peak is also observed for the absorption coefficient, with the largest divergence observed for

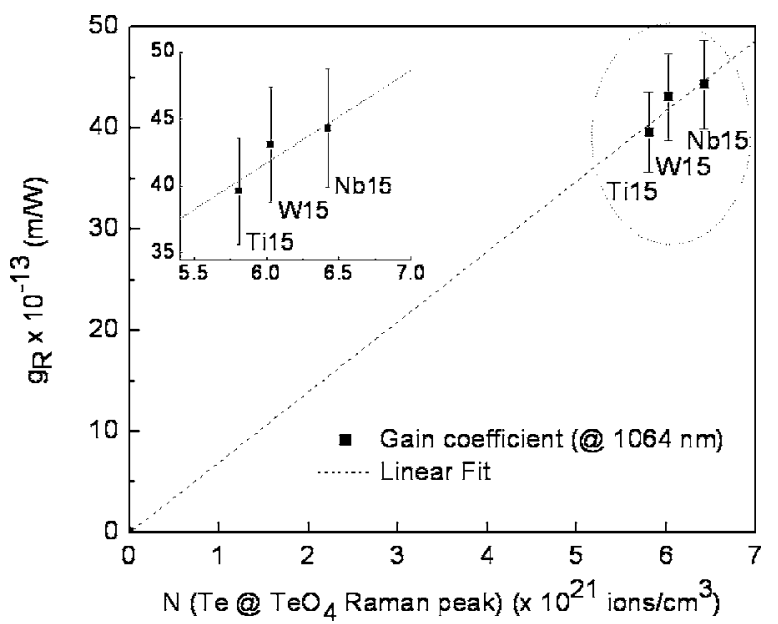

FIG. 8. Evolution of the peak Raman gain coefficient for the $\mathrm{TeO}_{4}$ vibration, as a function of the number density of Te ions present in that particular band, for $\mathrm{TeO}_{2}$-based glasses containing $d^{0}$ ions. Data have been normalized to the peak Raman gain coefficient of $\mathrm{SiO}_{2}\left(g_{R}=0.9 \pm 0.2 \times 10^{-13} \mathrm{~m} / \mathrm{W}\right.$ at $440 \mathrm{~cm}^{-1}$ ), using $1064 \mathrm{~nm}$ pumping. The dashed line corresponds to a linear fit of the data.

sample W15. Based on the results obtained, we can now correlate the absorption coefficient of the glass to the $\mathrm{TeO}_{3}$ to $\mathrm{TeO}_{4}$ ratio, showing a clear evidence of how the structural rearrangement of the tellurite glass matrix affects the optical absorption of the material.

In the case of Raman gain, the correlation between the $\mathrm{TeO}_{2}$ network structural transformation and the peak Raman gain coefficient at $665 \mathrm{~cm}^{-1}$ becomes more complicated. The peak Raman gain coefficient at the $\mathrm{TeO}_{4}$ vibration has been previously related to the number density of Te ions, but this assumption is valid within the same family, if the glasses exhibit similar polarizability. Even for the series with $d^{0}$ intermediate species, which show increasing refractive indices from titanium to tungsten, the polarizability is not identical, although it is reasonably comparable given the similar network structure of these three compositions with the presence of $d^{0}$ ions in oxygenated octahedral sites. Hence, it seems to be obvious to interpret the Raman gain coefficients at the $665 \mathrm{~cm}^{-1} \mathrm{TeO}_{4}$ vibration, for the three different compositions with $d^{0}$ intermediate species. Observing the Raman spectra illustrated in Figs. 4(a) and 4(b) one can see a different organization of the tellurium network for the Ti15 composition, as compared to $\mathrm{W} 15$ and $\mathrm{Nb} 15$, which results in the presence of more $\mathrm{Te}-\mathrm{O}-\mathrm{Te}$ chains indicating more depolymerization of the network. Thus intermediate type, its size, charge, and polarizability, all contribute to the observed structural role illustrated in the Raman data. Thus, the amount of $\mathrm{Te}$ ions at the $\mathrm{TeO}_{4}$ vibration can be estimated by the ratio of the integrated Raman cross section for this particular vibration as compared to the overall Raman spectrum from 325 to $800 \mathrm{~cm}^{-1}$, in order to obtain the overall contribution of the different Te-O vibrational modes. Notice that this estimation is only valid for compositions within the same glass family, or glasses with similar structural network. Therefore, Fig. 8 does not include the Ga15 and Pb15 compositions because, as previously stated, the $\mathrm{TeO}_{2}$ network structure varies for $d^{10}, n s^{2}$, and $d^{0}$ species; hence, it is not 
possible to correctly estimate and compare, from Raman spectra decomposition measurements, the contribution of $\mathrm{Te}$ ions at the $665 \mathrm{~cm}^{-1}$ Raman vibration for $\mathrm{GaO}_{1.5}$ and $\mathrm{PbO}$ to the results obtained for the $\mathrm{WO}_{3}, \mathrm{TiO}_{2}$ and $\mathrm{NbO}_{2.5}$ compositions. It follows that the number density of Te ions per unit volume at the $\mathrm{TeO}_{4}$ Raman band is proportional to the Raman gain coefficient at that particular vibration, as illustrated in Fig. 8. The inserted graph shows a magnification of the region of interest. The dashed line corresponds to a linear fit of the data, which gives a direct correlation between the number density of Te ions at the $665 \mathrm{~cm}^{-1}$ Raman band and its corresponding Raman gain coefficient. This result shows a direct link between the tellurite network and the corresponding Raman gain coefficient at the $665 \mathrm{~cm}^{-1}$ Raman vibration.

From the results obtained regarding the thermal stability $\left(T_{x}-T_{g}\right)$, the absorption coefficients from Fig. 6 and the Raman gain results shown in Fig. 4(b), one can conclude that the binary glass systems $\mathrm{TeO}_{2}-\mathrm{TiO}_{2}$ and $\mathrm{TeO}_{2}-\mathrm{Nb}_{2} \mathrm{O}_{5}$ appear to be the most promising candidates for future gain applications.

\section{CONCLUSION}

This paper summarizes results obtained on different binary tellurite glasses that were fabricated to investigate the influence of modifier oxides to the tellurite network. By keeping the examined glass networks simple, it was possible to clearly define the structural role of the modifier oxide and its contribution to other important physical and optical properties of these glasses. The results obtained demonstrate that there is a clear correlation between the glass network structure and the corresponding optical properties. The thermal stability of the glasses is increased with the addition of $d^{0}$ species, for the restricted number of glasses containing $d^{0}$ species studied in this paper. Moreover, the absorption of the material appears to be related to the $\mathrm{TeO}_{3}$ to $\mathrm{TeO}_{4}$ ratio, as illustrated by the XPS and Raman results where the absorption coefficient is higher for glasses with more $\mathrm{TeO}_{3}$ units, and equal $\mathrm{TeO}_{2}$ molar concentration. Lastly, this study confirms results seen previously whereby the Raman gain coefficient at the $\mathrm{TeO}_{4}$ Raman peak is directly proportional to the number density of $\mathrm{Te}$ ions contributing to this vibrational mode. The results here illustrate for the first time the strong influence of the surrounding network environment, as defined by the specific modifier oxide, on the $\mathrm{TeO}_{3}$ Raman vibration, and a clear enhancement in the Raman gain coef- ficient when the $\mathrm{TeO}_{2}$ network is combined with other highly polarizable species such as $d^{0}$ ions and $n s^{2}$ Lewis lone pair entities.

Based on the results obtained in this paper one can conclude that of the simple binary glass systems studied, $\mathrm{TeO}_{2}$ $-\mathrm{TiO}_{2}$ and $\mathrm{TeO}_{2}-\mathrm{Nb}_{2} \mathrm{O}_{5}$ appear to be the most promising candidates for future high gain discrete Raman amplification applications, based on their Raman gain behavior, optical absorption, and thermal stability.

\section{ACKNOWLEDGMENT}

This work was carried out with the support of a number of research, equipment, and educational grants, including NSF Grants Nos. ECS-0123484, ECS-0225930, INT0129235, NSF IGERT Grant No. DGE-0114418, NSF-CNRS Grant No. 13050, and DARPA Contract No. HR 00110410002 .

${ }^{1}$ E. Fargin et al., J. Non-Cryst. Solids 203, 96 (1996).

${ }^{2}$ B. Jeansannetas et al., J. Solid State Chem. 146, 329 (1999).

${ }^{3}$ M. D. O’Donnell, C. A. Miller, D. Furniss, V. K. Tikhomirov, and A. B. Seddon, J. Non-Cryst. Solids 331, 48 (2003).

${ }^{4}$ T. Sekiya, N. Mochida, A. Ohtsuka, and M. Tonokawa, J. Non-Cryst. Solids 144, 128 (1992).

${ }^{5}$ A. Mori, H. Masuda, K. Shikano, K. Oikawa, K. Kato, and M. Shimizu, Electron. Lett. 37, 1442 (2001).

${ }^{6}$ R. Stegeman et al., Opt. Lett. 28, 1126 (2003).

${ }^{7}$ C. Rivero, K. Richardson, R. Stegeman, G. Stegeman, T. Cardinal, E. Fargin, M. Couzi, and V. Rodriguez, J. Non-Cryst. Solids 345\&346, 396 (2004).

${ }^{8}$ G. Dai, F. Tassone, A. Li Bassi, V. Russo, C. E. Bottani, and F. D'Amore, IEEE Photonics Technol. Lett. 16, 1011 (2004).

${ }^{9}$ R. Stegeman et al., Opt. Express 13, 1144 (2005).

${ }^{10}$ V. G. Plotnichenko, V. V. Koltashev, V. O. Sokolov, E. M. Dianov, I. A. Grishin, and M. F. Churbanov, Opt. Lett. 30, 1156 (2005).

${ }^{11}$ G. Senthil Murugan, T. Suzuki, and Y. Ohishi, Appl. Phys. Lett. 86, 161109 (2005).

${ }^{12}$ A. C. Boccara, D. Fournier, W. Jackson, and N. M. Amer, Opt. Lett. 5, 377 (1980).

${ }^{13}$ W. B. Jackson, N. M. Amer, A. C. Boccara, and D. Fournier, Appl. Opt. 20, 1333 (1981)

${ }^{14}$ U. Willamowski, T. Gro $\beta$, D. Ristau, and H. Welling, Proc. SPIE 2870, 483 (1996)

${ }^{15}$ U. Willamowski, D. Ristau, and E. Welsch, Appl. Opt. 37, 8362 (1998).

${ }^{16}$ C. Rivero, R. Stegeman, D. Talaga, M. Couzi, T. Cardinal, K. Richardson, and G. Stegeman, Opt. Express 13, 4759 (2005).

${ }^{17}$ M. E. Lines, Phys. Rev. B 43, 11978 (1991).

${ }^{18}$ R. H. Stolen, NIST Spec. Publ. 953, 139 (2000).

${ }^{19}$ M. N. Islam, Physical Principles (Springer, New York, 2004).

${ }^{20}$ P. Charton, L. Gengembre, and P. Armand, J. Solid State Chem. 168, 175 (2002).

${ }^{21}$ D. Ilieva, D. Dimitrov, Y. Dimitrief, and G. Bogachev, Phys. Chem. Glasses 40, 1 (1999).

${ }^{22}$ R. A. H. El-Mallawany, Tellurite Glasses Handbook: Physical Properties and Data (CRC, Boca Raton, FL, 2001).

${ }^{23}$ H. M. M. Moawad, H. Jain, R. El-Mallawany, T. Ramadan, and M. ElSharbiny, J. Am. Ceram. Soc. 85, 2655 (2002). 